\title{
CRESCIMENTO INICIAL DA CULTURA DA SOJA EM LATOSSOLO BRUNO COM DIFERENTES GRAUS DE COMPACTAÇÃO ${ }^{(1)}$
}

\author{
Franciani Rodrigues da Silva ${ }^{(2)}$, Jackson Adriano Albuquerque ${ }^{(3)}$ André da Costa $^{(4)}$
}

\begin{abstract}
RESUMO
A compactação do solo é um dos principais fatores que altera a qualidade do solo e o crescimento das culturas. $O$ objetivo deste trabalho foi determinar o grau de compactação que restringe o crescimento da cultura da soja num Latossolo Bruno alumínico típico. $O$ experimento foi realizado em casa de vegetação. $O$ solo utilizado foi coletado no município de Guarapuava, $P R$, na camada de $0-20 \mathrm{~cm}$. Esse possuía $570 \mathrm{~g} \mathrm{~kg}^{-1}$ de argila, $370 \mathrm{~g} \mathrm{~kg}^{-1}$ de silte e $60 \mathrm{~g} \mathrm{~kg}^{-1}$ de areia. Foi compactado para obtenção das densidades do solo de 0,$90 ; 0,96 ; 1,02 ; 1,08 ; 1,14 ; 1,20$; e $1,27 \mathrm{~kg} \mathrm{dm}^{-3}$, correspondendo a graus de compactação entre 75 e $105 \%$, que foram determinados pela relação entre a densidade do solo atual e a densidade do solo máxima, obtida pelo ensaio de Proctor Normal. Durante o período de cultivo da soja avaliaram-se o crescimento radicular e a parte aérea, além da evapotranspiração diária. Aos 60 dias após a emergência, determinou-se a massa seca da parte aérea e das raízes. Qualquer aumento no grau de compactação acima de $75 \%$ reduz o crescimento das raízes na camada compactada; entretanto, as raízes não crescem quando o grau de compactação é igual ou superior a $105 \%$. Quando o grau de compactação é superior a $82 \%$, a altura das plantas diminui e quando é superior a 87 e $93 \%$ reduz respectivamente a massa da matéria seca da parte aérea e a evapotranspiração. Assim, o grau de compactação restritivo à cultura da soja depende do atributo que está sendo avaliado.
\end{abstract}

Termos de indexação: compactação do solo, matéria seca das plantas, desenvolvimento radicular, evapotranspiração.

(1) Parte da Tese de Doutorado da primeira autora apresentada à Universidade do Estado de Santa Catarina - UDESC. Recebido para publicação em 3 de junho de 2013 e aprovado em 4 de agosto de 2014 .

(2) Doutora em Ciência do Solo, Universidade do Estado de Santa Catarina - UDESC. Av. Luiz de Camões, 2090. CEP 88520-000 Lages (SC). E-mail: francianiagro@yahoo.com.br

(3) Professor, Departamento de Solos, CAV/UDESC. Bolsista do CNPq. E-mail: jackson.irai@gmail.com

(4) Doutor em Ciência do Solo, UDESC. E-mail: andrecosta.agro@hotmail.com 


\title{
SUMMARY: INITIAL GROWTH OF THE SOYBEAN CROP IN AN OXISOL WITH DIFFERENT DEGREES OF COMPACTION
}

\begin{abstract}
Soil compaction is a major factor affecting soil quality and crop growth. The objective of this study was to determine the degree of compaction that restricts soybean growth in a Latossolo Bruno aluminico típico (Oxisol). The experiment was conducted in a greenhouse, and the soil used was collected in Guarapuava, PR, Brazil, from the $0-20 \mathrm{~cm}$ layer. The soil consisted of $570 \mathrm{~g} \mathrm{~kg}^{-1}$ of clay, $370 \mathrm{~g} \mathrm{~kg}^{-1}$ of silt, and $60 \mathrm{~g} \mathrm{~kg}^{-1}$ of sand. The soil was artificially compacted to obtain bulk densities of 0.90, 0.96, 1.02, 1.08, 1.14, 1.20, and $1.27 \mathrm{~kg} \mathrm{dm}^{-3}$, corresponding to degrees of compaction between 75 and $105 \%$, which was determined from the ratio between the current bulk density and maximum bulk density obtained from the Normal Proctor test. Root and shoot growth were determined during soybean cropping, as well as daily evapotranspiration. The dry matter of roots and shoots was determined at 60 days after emergence. Any increase in the degree of compaction above $75 \%$ reduces root growth in the compacted layer, and roots do not grow when the degree of compaction is $105 \%$ or more. Plant height decreases when the degree of compaction is greater than $82 \%$, and shoot dry matter and evapotranspiration reduce when the degree of compaction is over 87 and $93 \%$, respectively. Thus, the degree of compaction restrictive to the soybean crop depends on plant characteristic being measured.
\end{abstract}

Index terms: soil compaction, plant dry matter, root development, evapotranspiration.

\section{INTRODUÇÃO}

A mecanização agrícola facilita o trabalho do homem no campo, embora em alguns sistemas de manejo possa compactar o solo por meio da compressão causada pela aplicação de energia mecânica (Reichert et al., 2007). Em áreas cultivadas, a principal energia de compactação é aplicada por máquinas e implementos agrícolas, o que diminui o volume de poros do solo.

Por estar diretamente relacionada ao aumento de massa ou à redução do espaço poroso, a compactação tem estreita relação com algumas propriedades físicas e mecânicas do solo. Em solos compactados, a densidade do solo (Ds) aumenta e a porosidade e a permeabilidade diminuem (Reichert et al., 2007). Essas alterações interferem na retenção, no movimento e na disponibilidade de água (Reichert et al., 2011); com isso, os mecanismos que governam o fluxo de nutrientes no solo e sua absorção pelas plantas são influenciados (Medeiros et al., 2005). Além disso, ao reduzir o tamanho dos poros e sua continuidade, diminui as trocas gasosas e a quantidade de oxigênio disponível na rizosfera, o que prejudica os processos metabólicos da planta (Queiroz-Voltan et al., 2000), a transpiração e o acúmulo de matéria seca (Berlato et al., 1986).

Além dessas alterações, a compactação influencia direta e indiretamente o crescimento das raízes, em razão do aumento da resistência à penetração. A resistência à penetração crítica ao desenvolvimento de raízes de diversas plantas pode variar entre $1,0 \mathrm{e}$ 4,0 MPa (Rosolem et al., 1999). Contudo, a resistência entre 2,0 e 2,5 MPa tem sido a faixa mais utilizada como limitante ao desenvolvimento das raízes (Taylor et al., 1966). Embora limitante, a maioria das raízes se desenvolve em solos com resistência à penetração acima desses valores, em razão da capacidade de explorarem zonas de menor resistência como poros entre unidades estruturais. Para tal, as raízes modificam sua morfologia, com desenvolvimento de raízes laterais mais finas, as quais procuram pontos de menor resistência (Tavares Filho et al., 2001). Além disso, em condições extremas, as raízes enviam sinais à parte aérea, informando que as condições para o desenvolvimento da planta estão restritas, sendo necessário reduzir a taxa de crescimento, o que diminui a produtividade das culturas (Taylor \& Brar, 1991). Moraes et al. (1995) verificaram num Latossolo Roxo de textura argilosa que, em níveis mais altos de compactação, a resistência do solo à penetração de raízes foi maior. Sendo assim, as raízes de plantas de soja não conseguiram aprofundar no perfil do solo quando a densidade foi de $1,23 \mathrm{~kg} \mathrm{dm}^{-3}$.

Todavia, é importante ressaltar que a magnitude dos efeitos da compactação do solo é determinada principalmente pela classe textural do solo, pelos sistemas de rotação de culturas utilizados, pelo tempo de uso dos diferentes sistemas de manejo e pela condição de umidade do solo em que são realizadas as operações de campo (Secco et al., 2009).

O grau de compactação tem sido utilizado para caracterizar a relação entre compactação e crescimento das culturas (Collares et al., 2008). Essa variável é obtida pela divisão da Ds que está sendo cultivado pela Ds máxima obtida no ensaio de Proctor Normal (Håkansson \& Lipiec, 2000). Essa relação é útil na caracterização da compactação e da resposta das culturas em diferentes tipos de solos, principalmente em razão da facilidade de medição para indicar mudanças nos atributos físicos como macroporosidade, permeabilidade ao ar e resistência à penetração do solo (Carter, 1990). Em solo arenoso de clima temperado, Carter (1990) constatou que a máxima produtividade de trigo e de cevada foi em grau de compactação de 81 \%. Em Latossolo Vermelho, 
Suzuki et al. (2007) constataram que o grau de compactação ótimo para a cultura da soja foi de $86 \%$. Quando o grau de compactação é menor que $80 \%$, esse pode influenciar a produtividade das culturas por causa, principalmente, da redução da capacidade de armazenagem de água no solo (Lindstron \& Voorhees, 1994). Logo, o efeito da compactação está relacionado com o tipo de solo e planta e principalmente com a umidade do solo.

Apesar do grande número de estudos relacionando crescimentos de culturas agrícolas em diferentes níveis de compactação, há carência de trabalhos com Latossolos Brunos que ocorrem com frequência no sul do Brasil. Esse solo possui estrutura característica denominada de "pó-de-café", comum em solos oxídicos, a qual confere ao solo agregados estáveis e resistentes e menor densidade, mesmo no plantio direto (Costa, 2001). Sendo assim, o objetivo deste trabalho foi determinar o grau de compactação que restringe o crescimento da cultura da soja num Latossolo Bruno alumínico típico de textura argilosa, localizado na região de Guarapuava, PR.

\section{MATERIAL E MÉTODOS}

O experimento foi conduzido em casa de vegetação. O solo utilizado foi um Latossolo Bruno alumínico típico de textura argilosa, coletado na camada arável $(0-20 \mathrm{~cm})$, na área experimental da Fundação Agrária de Pesquisa Agropecuária, localizada no município de Guarapuava, PR. Esse solo possuía $570 \mathrm{~g} \mathrm{~kg}^{-1} \mathrm{de}$ argila, $370 \mathrm{~g} \mathrm{~kg}^{-1}$ de silte, $60 \mathrm{~g} \mathrm{~kg}^{-1}$ de areia e $47 \mathrm{~g} \mathrm{~kg}^{-1} \mathrm{de}$ carbono orgânico.

O solo foi seco ao ar e passado em peneira com malha de 2,0 $\mathrm{mm}$ e homogeneizado. $\mathrm{O} \mathrm{pH}$ do solo foi elevado para 6,0 com calcário dolomítico (CaO: $29 \%$, MgO: 19 \% e PRNT: 90 \%), conforme recomendação da CQFS-RS/SC (2004) para a soja. Após 70 dias de incubação do solo, os vasos foram montados com três anéis de PVC sobrepostos, com diâmetro interno de $100 \mathrm{~mm}$. A altura de cada anel (superior, intermediário e inferior) foi de $100 \mathrm{~mm}$. Os anéis superiores e inferiores foram preenchidos com as porções de amostra do solo com massa determinada, para que apresentassem densidade de $0,90 \mathrm{~kg} \mathrm{dm}^{-3}$. Para os anéis intermediários, as amostras tinham uma massa para resultar em Ds $\left(\mathrm{kg} \mathrm{dm}^{-3}\right)$ e grau de compactação (\%), respectivamente de: 0,90 (75); 0,96 (80); 1,02 (85); 1,08 (90); 1,14 (95); 1,20 (100); e 1,27 (105).

O grau de compactação foi definido pela relação entre a Ds atual e a máxima Ds, obtida pelo ensaio de Proctor Normal, segundo Associação Brasileira de Normas Técnicas (ABNT) pela norma NBR 7.182 (ABNT, 1986), que foi de $1,20 \mathrm{~kg} \mathrm{dm}^{-3}$ para o Latossolo Bruno. Para compactar o solo, utilizou-se uma prensa hidráulica no centro geométrico de um suporte de madeira com diâmetro ligeiramente inferior ao vaso.
Antes da implantação do experimento, determinaram-se a macroporosidade $(-6 \mathrm{kPa})$, a capacidade de campo $(-10 \mathrm{kPa})$, a porosidade total (diferença de umidade entre o solo saturado e o solo seco), a porosidade de aeração (diferença entre a porosidade total e capacidade de campo a $80 \%$ ) e o ponto de murcha permanente $(-1500 \mathrm{kPa})$ de todos os anéis da camada intermediária (Embrapa, 1997). Aos pares de dados de tensão e umidade volumétrica, foi ajustada a curva característica de retenção de água (CRA) por meio do modelo proposto por van Genuchten (1980).

Também foram avaliadas as equações desenvolvidas por Jones (1983) e por Reichert et al. (2009) para estimativa da densidade crítica (Dc) do Latossolo Bruno, com o objetivo de testar a aplicabilidade delas para o solo avaliado. Em relação às equações, Jones (1983) definiu a densidade crítica como a densidade em que o crescimento das raízes reduziu em $20 \%$, comparado ao máximo crescimento quando o solo foi mantido na capacidade de campo, avaliando solos com ampla faixa de porcentagens de argila e silte. A densidade em que ocorre restrição de raízes $\left(\mathrm{Dc}_{\text {Jones }}\right)$ pode ser estimada pelas seguintes equações: $\mathrm{Dc}_{\text {Jones }}=1,77-0,00063$ argila $\left(\mathrm{R}^{2}=0,82\right)$ ou $\mathrm{Dc}_{\text {Jones }}=-1,83-0,00043$ (argila + silte) $\left(\mathrm{R}^{2}=0,76\right)$. Reichert et al. (2009) definiram a densidade crítica do solo como a densidade em que o intervalo hídrico ótimo torna-se zero ou a densidade em que ocorre redução do crescimento de raízes ou do rendimento de grãos em uma ampla variedade de solos. A densidade em que o IHO torna-se zero pode ser estimada pelas equações: $\mathrm{Dc}_{\mathrm{IHO}}=1,84-0,00078$ argila ou $\mathrm{Dc}_{\mathrm{IHO}}=1,91$ - 0,00067 (argila + silte), e a densidade em que ocorre restrição do crescimento de raízes ou do rendimento de grãos pode ser estimada pelas equações: $\mathrm{Dc}_{\text {Rest }}=1,86$ - 0,00071 argila ou Dc $\mathrm{c}_{\text {Rest }}=1,98-0,00061$ (argila + silte).

No momento da montagem dos vasos, foram sobrepostos os anéis intermediários com as amostras de solo previamente compactadas; sobre os anéis inferiores e sobre os intermediários acoplaram-se os superiores, que foram preenchidos com amostra de solo até a altura de $90 \mathrm{~mm}$, reservando-se $10 \mathrm{~mm}$ para receber a água das irrigações e para evitar perdas de solo durante esse processo. Para evitar o crescimento de raízes entre a parede do vaso e o solo compactado (anel intermediário), foram coladas fitas entre a parede do vaso $(2,0 \mathrm{~cm}$ de fita) e a superfície superior do solo (0,5 cm de fita). A união e a vedação entre os três anéis foram feitas com fita adesiva. $\mathrm{Na}$ base dos vasos tinham pequenos orifícios para permitir o fluxo de água.

Em cada vaso, foram semeadas quatro sementes de soja (Glycine $\max$ ), variedade NS 4823, na profundidade de $5,0 \mathrm{~mm}$. Sete dias após a semeadura, realizou-se o desbaste, mantendo-se duas plantas por vaso. Semanalmente, fez-se a medição da altura das plantas. A umidade do solo foi controlada por meio de 
pesagem diária dos vasos em balança de precisão e posterior irrigação com o auxílio de um regador manual, a fim de repor a água evapotranspirada, mantendo a umidade do solo a $80 \%$ da capacidade de campo. A água evapotranspirada foi determinada a partir do $45^{\circ}$ dia de implantação até o término da condução do mesmo.

Após 60 dias da emergência, as plantas foram cortadas rente ao solo para definir a massa de matéria seca em estufa a $60^{\circ} \mathrm{C}$ por $48 \mathrm{~h}$. Em seguida, as três camadas foram separadas; na camada intermediária, determinou-se a resistência à penetração (seis repetições por amostra) na parte central do anel, com um penetrômetro eletrônico de bancada (modelo MA 933, marca Marconi), composto de um atuador linear elétrico com motor, um painel para controle da velocidade e uma base metálica para sustentação do conjunto mecânico e da amostra durante o ensaio, além de uma célula de carga com capacidade nominal de $20 \mathrm{~kg}$ acoplada a um microcomputador. Utilizou-se um cone de $3 \mathrm{~mm}$ de diâmetro, que foi introduzido nas amostras de solo até a profundidade de $5 \mathrm{~cm}$, com velocidade constante de $10 \mathrm{~cm} \mathrm{~min}^{-1}$ e leituras a cada $1 \mathrm{~s}$. Para evitar o efeito de bordadura, os cinco valores iniciais e finais de resistência não foram utilizados para calcular a resistência à penetração média do solo. No momento da definição da resistência à penetração, a umidade do solo em todos os tratamentos era de $80 \%$ da capacidade de campo.

Simultaneamente à separação das três camadas, as raízes de cada camada foram separadas do solo por jatos de água e secas em estufa a $60{ }^{\circ} \mathrm{C}$ por $48 \mathrm{~h}$, para determinar a massa de matéria seca das raízes.

$\mathrm{O}$ delineamento experimental foi inteiramente casualizado, com quatro repetições. Os dados de solo e planta foram submetidos à análise de regressão, a $5 \%$, pelo teste $\mathrm{F}$, utilizando o programa estatístico SAS 9.2 (SAS, 2010).

\section{RESULTADOS E DISCUSSÃO}

Com a elevação do grau de compactação de 75 a $105 \%$, aumentou a resistência à penetração de $1,0 \mathrm{a}$ 7,9 MPa e a massa de matéria seca das raízes (MSR) na camada superior; entretanto, reduziu a macroporosidade, a porosidade de aeração do solo, a altura das plantas, a massa de matéria seca das raízes nas camadas intermediária e inferior e a de matéria seca da parte aérea (MSPA) (Figura 1). Com a compactação, a macroporosidade diminuiu de 0,18 para $0,03 \mathrm{~m}^{3} \mathrm{~m}^{-3}$; no entanto, como a umidade foi mantida a $80 \%$ da capacidade de campo, a porosidade de aeração variou de 0,29 para $0,16 \mathrm{~m}^{3} \mathrm{~m}^{-3}$ (Figura 1b,c). Como o bom crescimento e o bom desenvolvimento das plantas, assim como a qualidade do solo, dependem de um limite mínimo de porosidade de aeração de $0,10 \mathrm{~m}^{3} \mathrm{~m}^{-3}$ (Xu et al., 1992), pode-se afirmar que não houve restrição de aeração mesmo nos maiores graus de compactação. Logo, os graus de compactação avaliados não comprometeram a difusão de gases nesse Latossolo, pois a umidade foi controlada. Já em condições de campo, a condição meteorológica não pode ser controlada; durante período muito chuvoso pode ocorrer restrição de aeração quando o solo está compactado.

Na camada superior, a MSR aumentou até o grau de compactação de $95 \%$, indicando que houve restrição de crescimento em profundidade (Figura 1f), e as raízes não se aprofundaram. Em contrapartida, tanto na camada intermediária (compactada) como na inferior a MSR diminuiu linearmente com o aumento do grau de compactação. O aumento da MSR na camada superior ocorreu em razão da compactação subsuperficial do solo, que inibiu o crescimento radicular da soja na camada compactada e levou a maior crescimento ou confinamento na camada superior. Tal fato corroborou os resultados encontrados por Rosolem et al. (1994), os quais verificaram maior concentração de raízes na camada de $0-15 \mathrm{~cm}$ de um Latossolo Vermelho arenoso na maior densidade avaliada $\left(1,72 \mathrm{~kg} \mathrm{dm}^{-3}\right)$. Esses autores observaram que as raízes da soja atravessaram a camada intermediária (compactada) até a densidade de $1,48 \mathrm{~kg} \mathrm{dm}^{-3}$. Moraes et al. (1995) verificaram que o desenvolvimento vertical das raízes das plantas de soja ficou impedido quando a Ds era de $1,23 \mathrm{~kg} \mathrm{dm}^{-3}$, num Latossolo Roxo de textura argilosa. Para Alvarenga et al. (1996), a densidade entre $1,27 \mathrm{e} 1,57 \mathrm{~kg} \mathrm{dm}^{-3}$ é restritiva ao desenvolvimento das raízes das plantas, sendo dependente da classe textural e do teor de matéria orgânica do solo.

A diminuição linear da MSR tanto na camada intermediária como na inferior (Figura 1f) ocorreu em razão da diminuição do aprofundamento das raízes ao solo, conforme aumentou o grau de compactação. Resultado semelhante foi observado por Müller et al. (2001) com plantas de adubação verde de inverno num Latossolo Vermelho-Escuro. Na camada com grau de compactação de $100 \%$, praticamente não houve desenvolvimento de raiz, ao passo que no grau de compactação de $105 \%$ as raízes não conseguiram atravessar a camada compactada, não havendo, dessa forma, raízes na camada inferior. Assim, verificou-se que as raízes da soja são sensíveis à compactação do solo e não se desenvolvem verticalmente quando o Latossolo Bruno está com grau de compactação igual ou acima de $105 \%$. Logo, o desenvolvimento da parte aérea ficou comprometido, uma vez que a habilidade das plantas em absorver água e nutrientes depende da distribuição de raízes, que é função principalmente de limitações físicas do solo (Alvarenga \& Cruz, 2003).

A partir do grau de compactação de 82 e $87 \%$ diminui, respectivamente, a altura das plantas e a MSPA. A máxima produção de MSPA da soja observada no grau de compactação de $87 \%$ está abaixo da observada por Silva et al. (2006) em experimento com plantas cultivadas em vasos com diferentes graus 

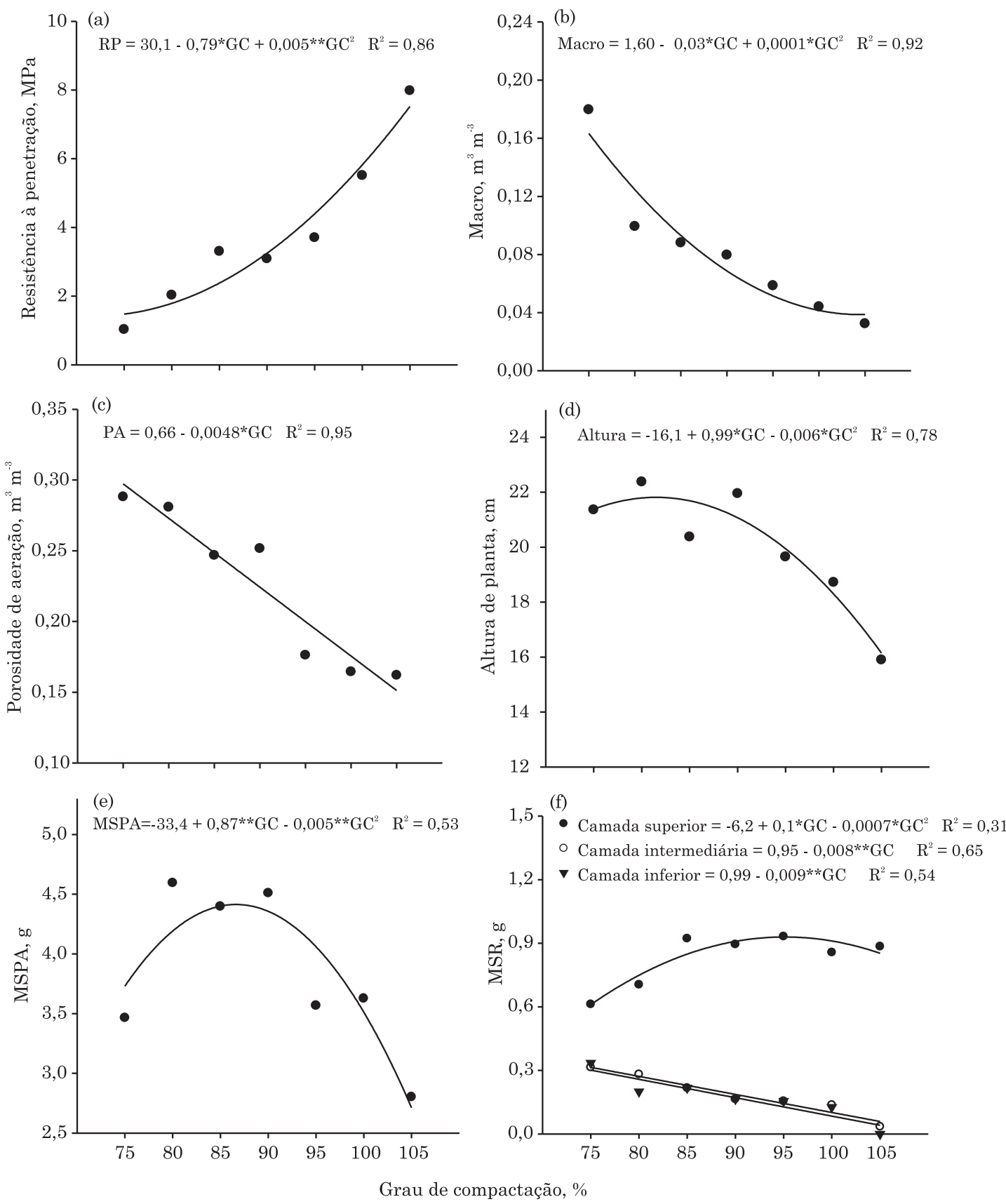

Figura 1. Resistência mecânica do solo à penetração - RP (a), macroporosidade - Macro (b), porosidade de aeração - PA (c), altura de plantas - Altura (d), massa de matéria seca da parte aérea - MSPA (e), massa de matéria seca da raiz (MSR) nas camadas superior, intermediária e inferior (f) em diferentes graus de compactação de um Latossolo Bruno. * e **: significativos a 5 e $1 \%$, respectivamente.

de compactação num Latossolo Vermelho arenoso com $23 \mathrm{~g} \mathrm{~kg}^{-1}$ de C orgânico. O menor grau de compactação relaciona-se principalmente ao elevado teor de matéria orgânica desse Latossolo Bruno (47 $\left.\mathrm{g} \mathrm{kg}^{-1}\right)$ e ao maior teor de argila. Segundo Braida et al. (2006), a matéria orgânica tende a diminuir a Ds em razão da sua baixa densidade, de modo que, diminui também a Dc crítica ao crescimento radicular. Ao avaliar um Nitossolo Vermelho argiloso com $15 \mathrm{~g} \mathrm{~kg}^{-1}$ de C orgânico compactado subsuperficialmente com anéis de PVC sobrepostos, Foloni et al. (2006) observaram redução na produção de MSPA de soja acima da Ds de 1,56 $\mathrm{kg} \mathrm{dm}{ }^{-3}$. Num Latossolo Vermelho-Escuro de textura média com $16 \mathrm{~g} \mathrm{~kg}^{-1}$ de $\mathrm{C}$ orgânico, compactado em subsuperfície, Müller et al. (2001) obtiveram redução na produção de MSPA de diversas culturas na Ds de $1,58 \mathrm{~kg} \mathrm{dm}^{-3}$.

Considerando que a altura e a massa de matéria seca das plantas de soja foram maiores quando o grau de compactação foi de 82 e $87 \%$, respectivamente, é 
correto afirmar que esses valores possuem semelhança com os encontrados por Suzuki et al. (2007), em trabalho realizado no campo num Latossolo Vermelho com $654 \mathrm{~g} \mathrm{~kg}^{-1}$ de argila, $260 \mathrm{de} \mathrm{g} \mathrm{kg}^{-1}$ de silte e $85 \mathrm{~g} \mathrm{~kg}^{-1}$ de areia, em que o grau de compactação ótimo para a cultura da soja, considerando altura de plantas e rendimento, foi de $86 \%$. Segundo Lindstron \& Voorhees (1994), quando o grau de compactação é menor que $80 \%$ a produtividade de algumas culturas diminui, assim como quando esse é maior que $86 \%$ é considerado elevado e prejudicial ao desenvolvimento das culturas.

As diferenças no grau de compactação entre os diversos estudos podem estar relacionadas às diferenças de métodos, à duração dos experimentos, aos solos e às espécies utilizadas (Silva et al., 2006). É importante considerar a existência de diferenças entre a estrutura do solo observada no campo daquela notada em estudos em que o solo é compactado artificialmente. Isso ocorre porque no campo existe maior heterogeneidade em relação ao solo compactado artificialmente, com existência de zonas de maior e outras de menor densidade, além da existência de porosidade contínua originada pela atividade biológica, da fauna e das raízes (Lima et al., 2005). Além disso, em solos compactados artificialmente, a determinação da resistência à penetração não é capaz de identificar e integrar o efeito de rachaduras e de poros biológicos existentes no solo; porém, são nessas regiões de menor resistência que as raízes crescem, mesmo em solos com elevada resistência à penetração.

Em média, o aumento da Ds eleva a resistência à penetração durante todo o ciclo de cultivo. Entretanto, diferente de experimentos em casa de vegetação, no perfil a umidade muda muito com o ciclo da cultura (Kaiser, 2010). Assim, para uma mesma densidade, o solo pode ter diferentes resistências à penetração por causa das diferenças na umidade do solo. Quando ocorre restrição hídrica, aqueles solos mais densos comprometem o crescimento e a produção de MSPA da soja em razão da menor capacidade de crescimento e desenvolvimento das raízes no perfil, bem como prejudicam a absorção de água e nutrientes pelas plantas (Foloni et al., 2006). Assim, os efeitos da Ds no crescimento das culturas são dependentes da disponibilidade de água.

No menor grau de compactação do solo (75\%), a evapotranspiração diária foi de $5,6 \mathrm{~mm}$; com o aumento do grau de compactação para 80,85 e $93 \%$, a evapotranspiração aumentou para próximo de $7,5 \mathrm{~mm} \mathrm{dia}{ }^{-1}$ (Figura 2), mas diminuiu de forma acentuada para maiores graus de compactação. Essas taxas estão de acordo com o estudo de Berlato et al. (1986), os quais encontraram evapotranspiração diária em torno de $7 \mathrm{~mm}$ para a cultura da soja no início do estádio de florescimento.

A maior evapotranspiração nas menores densidades está relacionada ao maior desenvolvimento de plantas associada à maior disponibilidade de água no solo. Segundo Pereira et al. (2002), a evapotranspiração é influenciada por fatores como: condições ambientais, vegetação, tipo de solo e sistema de manejo. Um fator que também pode ter influenciado a maior evapotranspiração nas menores densidades está relacionado com o crescimento das raízes em profundidade, comparado ao solo mais compactado. Quanto maior é o sistema radicular da planta maior é o volume de solo explorado pelas raízes, visando o atendimento da demanda hídrica da atmosfera (Pereira et al., 2002).

A redução da evapotranspiração nos maiores graus de compactação está relacionada à formação de poros de menor diâmetro, os quais aumentam a energia de retenção e diminuem a disponibilidade de água e o crescimento das plantas. Segundo Tormena et al. (1998), a energia de retenção de água no solo regula em parte o processo evapotranspiratório, principalmente em razão de o conteúdo de água disponível refletir as alterações na estrutura e, portanto, na distribuição do tamanho dos poros. Em trabalho comparando diferentes sistemas de cultivo do solo, López \& Arrhé (1997) verificaram menor evapotranspiração no sistema de semeadura direta, comparado ao cultivo mínimo e convencional, alteração associada à maior resistência à penetração e à energia de retenção de água no solo, resultando em menor crescimento das plantas.

Portanto, nos graus de compactação entre 80 e $90 \%$, apesar de existirem restrições ao crescimento em altura e de produção de matéria seca da parte aérea, a evapotranspiração foi pouco influenciada, ficando próximo do máximo. Apesar de ter restringido o crescimento radicular a partir de graus de compactação de $75 \%$ na camada compactada, como o

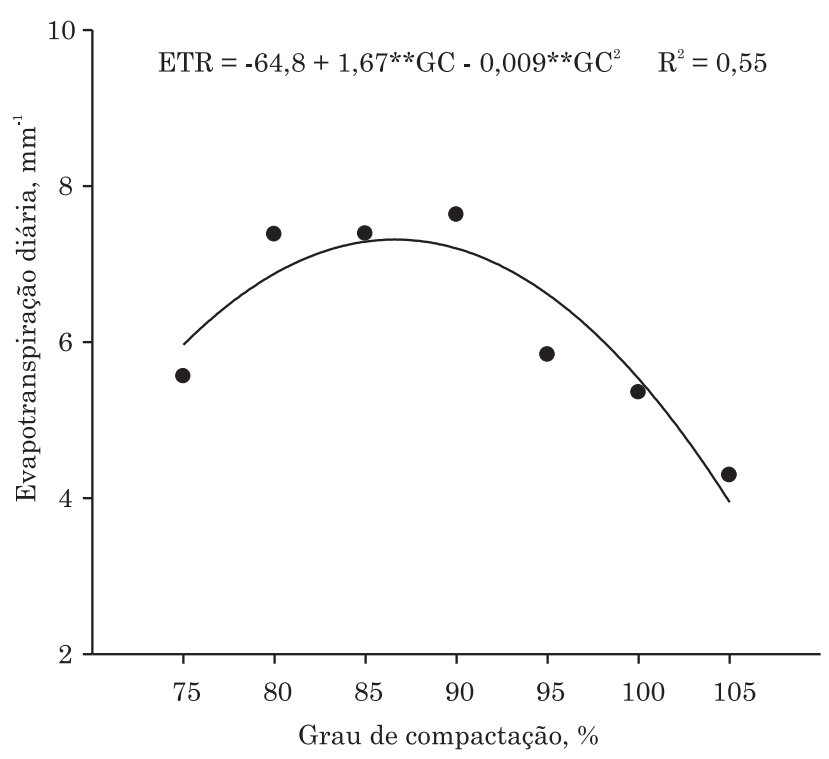

Figura 2. Evapotranspiração diária nas diferentes densidades num Latossolo Bruno. * e **: significativos a 5 e $1 \%$, respectivamente. 
solo estava com umidade de $80 \%$ da capacidade de campo, a evapotranspiração não foi restringida. Assim, novos estudos devem ser conduzidos para avaliar a relação entre o grau de compactação e os atributos da cultura quando ocorrem deficits hídricos.

As densidades críticas estimadas pelas equações de Jones (1983) e de Reichert et al. (2009) (Quadro 1) foram superiores às observadas neste trabalho, que variaram de 1,28 a $1,46 \mathrm{~kg} \mathrm{dm}^{-3}$, correspondendo a graus de compactação respectivamente de $107 \mathrm{e}$ $121 \%$. Neste estudo, a densidade do Latossolo Bruno tornou-se crítica quando estava acima de $1,14 \mathrm{~kg} \mathrm{dm}^{-3}$, que corresponde a um grau de compactação de $95 \%$. Tal diferença está no fato de que esse Latossolo Bruno possui estrutura característica denominada de "póde-café", que confere ao solo agregados estáveis e resistentes e menor densidade (Costa, 2001). Além disso, o alto teor de matéria orgânica, em razão da localização geográfica e elevada altitude, pode ter contribuído para diminuição da Dc do solo (Braida et al., 2006).

A curva de retenção de água no solo diferiu entre os diferentes graus de compactação (Figura 3). Nos graus de compactação entre 75 e $90 \%$, a retenção de água foi maior nas menores tensões $(0,1 \mathrm{e} 10 \mathrm{hPa}) \mathrm{e}$ menor nas maiores tensões (5.000 e $15.000 \mathrm{hPa}$ ). Isso aumentou a inclinação da curva entre as tensões de 10 e $1.000 \mathrm{hPa}$ nos menores graus de compactação, em que os parâmetros $\mathrm{n}$ e $\mathrm{m}$ foram maiores (Quadro 2), em relação aos observados nas curvas de retenção de água nos maiores graus de compactação (95, $100 \mathrm{e}$ 105 \%). Segundo Ramos et al. (2013), a menor retenção de água nas menores tensões deve-se à maior quantidade de poros de maior tamanho, os quais são responsáveis pela drenagem de água.

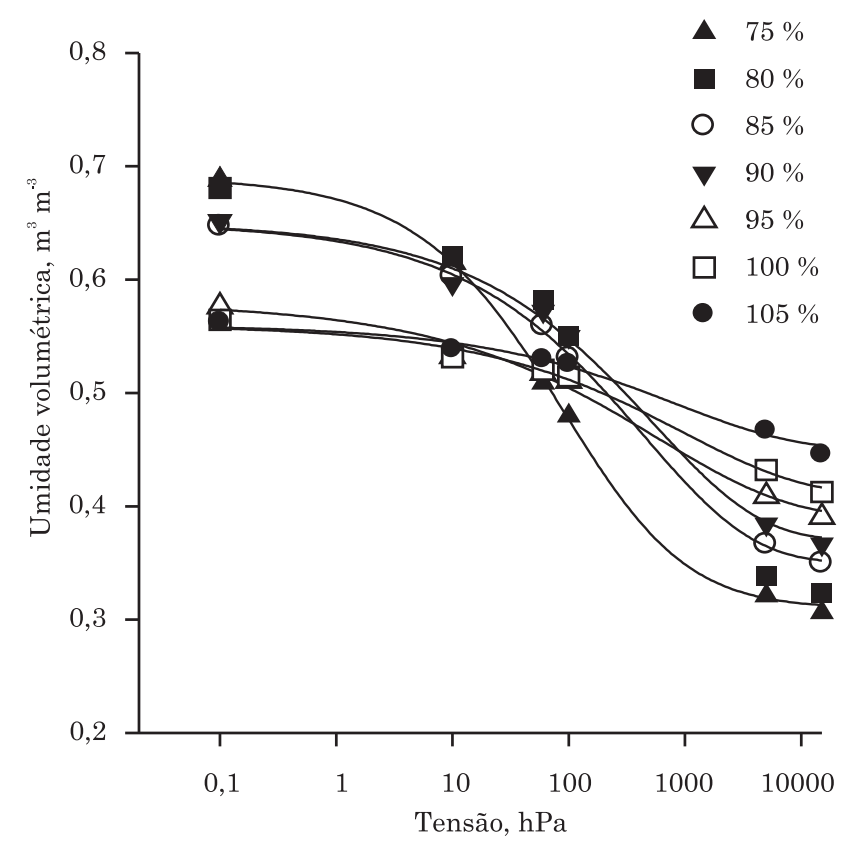

Figura 3. Curva de retenção de água nos diferentes graus de compactação.

Quadro 1. Densidade crítica e grau de compactação estimados para Latossolo Bruno utilizando as equações de Jones e de Reichert e colaboradores

\begin{tabular}{llcc}
\hline \multicolumn{1}{c}{ Autor } & \multicolumn{1}{c}{ Equação } & Densidade crítica & Grau de compactação \\
\hline & & $\mathrm{kg} \mathrm{dm}^{-3}$ & $\%$ \\
Reichert et al. (2009) & $\mathrm{Dc}_{\mathrm{IHO}}=1,84-0,00078$ argila & 1,39 & 116 \\
Reichert et al. (2009) & $\mathrm{Dc}_{\text {Rest }}=1,86-0,00071$ argila & 1,46 & 121 \\
Jones (1983) & $\mathrm{Dc}_{\text {Jones }}=1,77-0,00063$ argila & 1,41 & 118 \\
Reichert et al. (2009) & $\mathrm{Dc}_{\mathrm{IHO}}=1,91-0,00067$ (argila+silte) & 1,28 & 107 \\
Reichert et al. (2009) & $\mathrm{Dc}_{\text {Rest }}=1,98-0,00061$ (argila+silte) & 1,41 & 117 \\
Jones (1983) & $\mathrm{Dc}_{\text {Jones }}=1,83-0,00043$ (argila+silte) & 1,43 & 119 \\
\hline
\end{tabular}

Quadro 2. Parâmetros de ajuste das curvas de retenção de água, segundo o modelo de van Genuchten(1), para diferentes graus de compactação

\begin{tabular}{|c|c|c|c|c|c|}
\hline Grau de compactação & Porosidade total & Ponto de murcha permanente & $\alpha$ & $\mathbf{n}$ & $\mathbf{m}$ \\
\hline$\%$ & 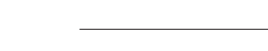 & $\mathrm{m}^{3} \mathrm{~m}^{-3}$ & & & \\
\hline 75 & 0,69 & 0,31 & 0,07 & 1,45 & 0,31 \\
\hline 80 & 0,68 & 0,32 & 0,02 & 1,55 & 0,36 \\
\hline 85 & 0,65 & 0,35 & 0,03 & 1,51 & 0,34 \\
\hline 90 & 0,65 & 0,37 & 0,02 & 1,58 & 0,37 \\
\hline 95 & 0,58 & 0,39 & 0,04 & 1,38 & 0,27 \\
\hline 100 & 0,56 & 0,41 & 0,03 & 1,44 & 0,30 \\
\hline 105 & 0,56 & 0,45 & 0,02 & 1,40 & 0,29 \\
\hline
\end{tabular}

(1) van Genuchten (1980). 
Com o aumento dos graus de compactação, a retenção de água foi menor principalmente nas menores tensões $(0,1$ e $10 \mathrm{hPa})$, ao passo que, nas maiores tensões, principalmente nas de 5.000 e $10.000 \mathrm{hPa}$, ocorreu o inverso. Isso demonstra que com o aumento da compactação há transformação de parte dos macroporos em microporos e consequentemente o volume de água retido nas maiores tensões aumenta, o que reduz a inclinação da curva de retenção de água.

\section{CONCLUSÕES}

1. O aumento do grau de compactação reduz a macroporosidade e a porosidade de aeração e aumenta a resistência do solo à penetração e a retenção de água no solo nas maiores tensões.

2. A altura das plantas de soja diminuiu a partir do grau de compactação de $82 \%$; e a produção de matéria seca da raiz e da parte aérea, a partir de 75 e $87 \%$, respectivamente. A evapotranspiração reduziu a partir do grau de compactação de $93 \%$. Assim, o grau de compactação restritivo à cultura da soja depende do atributo que está sendo avaliado.

\section{LITERATURA CITADA}

ASSOCIAÇÃO BRASILEIRA DE NORMAS TÉCNICAS ABNT. NBR 7182: Solo: Ensaio de compactação. Rio de Janeiro, ABNT, 1986. 10p.

ALVARENGA, R.C. \& CRUZ, J.C. Manejo de solos e agricultura irrigada. In: RESENDE, M.; ALBUQUERQUE, P.E.P. \& COUTO, L., eds. A cultura do milho irrigado. Brasília, Embrapa Informação Tecnológica, 2003. p.70-106.

ALVARENGA, R.C.; COSTA, L.M.; MOURA FILHO, W. \& REGAZZI, A.J. Crescimento de leguminosas em camadas de solo compactadas artificialmente. R. Bras. Ci. Solo, 20:319-326, 1996.

BERLATO, M.A.; MATZENAUER, R. \& BERGAMASCHI, H. Evapotranspiração máxima da soja e relações com a evapotranspiração calculada pela equação de Penman, evaporação do tanque "classe A" e radiação solar global. Agron. Sulriograndense, 22:251-259, 1986.

BRAIDA, J.A.; REICHERT, J.M.; VEIGA, M. \& REINERT, D.J. Resíduos vegetais na superfície e carbono orgânico do solo e suas relações com a densidade máxima obtida no ensaio Proctor. R. Bras. Ci. Solo, 30:605-614, 2006.

CARTER, M.R. Relative measures of soil bulk density to characterize compaction in tillage studies on fine sandy loams. Can. J. Soil Sci., 70:425-433, 1990.

COLLARES, G.L.; REINERT, D.J.; REICHERT, J.M. \& KAISER, D.R. Compactação de um Latossolo induzida pelo tráfego de máquinas e sua relação com o crescimento e produtividade de feijão e trigo. R. Bras. Ci. Solo, 32:933-942, 2008.
COSTA, F.S. Propriedades físicas e produtividade de culturas de um Latossolo Bruno sob sistemas de manejo do solo em experimentos de longa duração. Lages, Universidade do Estado de Santa Catarina, 2001. 98p. (Dissertação de Mestrado)

COMISSÃO DE QUÍMICA E FERTILIDADE DO SOLO CQFS-RS/SC. Manual de adubação e de calagem para os estados do Rio Grande do Sul e de Santa Catarina. 10.ed. Porto Alegre, Sociedade Brasileira de Ciência do Solo/Núcleo Regional Sul, 2004. 400p.

EMPRESA BRASILEIRA DE PESQUISA AGROPECUÁRIA - EMBRAPA. Serviço Nacional de Levantamento e Classificação dos Solos. Manual de métodos de análise de solo. 2.ed. Rio de Janeiro, Embrapa, 1997. 212p.

FOLONI, J.S.S.; LIMA, S.L. \& BÜLL, L.T. Crescimento aéreo e radicular da soja e de plantas de cobertura em camadas compactadas de solo. R. Bras. Ci. Solo, 30:49-57, 2006.

HÅKANSSON, I. \& LIPIEC, J. A review of the usefulness of relative bulk density values in studies of soil structure and compaction. Soil Till. Res., 53:71-85, 2000.

JONES, C.A. Effect of soil texture on critical bulk densities for root growth. Soil Sci. Soc. Am. J., 47:1208-1211, 1983.

KAISER, D.R. Propriedades físico-hídricas e dinâmica da água no solo. Santa Maria, Universidade Federal de Santa Maria, 2010. 146p. (Tese de Doutorado)

LIMA, H.V.; LIMA, C.L.R.; LEÃO, T.P.; COOPER, M.; SILVA, A.P. \& ROMERO, R.E. Tráfego de máquinas agrícolas e alterações de bioporos em área sob pomar de laranja. R. Bras. Ci. Solo, 29:677-684, 2005.

Lindstron, M.J. \& VOORHEES, W.B. Response of temperate crops to soil compaction. In: SOANE, B.D. \& van OUWERKERK, C., eds. Soil compaction in crop production. London, Elsevier, 1994. p.265-286. (Developments in Agricultural Engineering, 2)

LÓPEZ, M.V. \& ARRHE, J.L. Growth, yield and water use efficiency of winter barley in response to conservation tillage in a semi-arid region of Spain. Soil Till. Res., 44:35-54, 1997.

MEDEIROS, R.D.; SOARES, A.A. \& MENDES, G.R. Compactação do solo e manejo da água. I: Efeitos sobre a absorção de $\mathrm{N}, \mathrm{P}, \mathrm{K}$, massa seca de raízes e parte aérea de plantas de arroz. Ci. Agrotec., 29:940-947, 2005.

MORAES, M.H.; BENEZ, S.H. \& LIBARDI, P.L. Efeitos da compactação em algumas propriedades físicas do solo e seu reflexo no desenvolvimento das raízes de plantas de soja. Bragantia, 52:393-403, 1995.

MÜLleR, M.M.L.; CECCON, G. \& ROSOlEM, C.A. Influência da compactação do solo em subsuperfície sobre o crescimento aéreo e radicular de plantas de adubação verde de inverno. R. Bras. Ci. Solo, 25:531538, 2001.

PEREIRA, A.R.; ANGELOCCI, L.R. \& SENTELHAS, P.C. Agrometeorologia: Fundamentos e aplicações práticas. Guaíba, Agropecuária, 2002. 478p. 
QUEIROZ-VOLTAN, R.B.; NOGUEIRA, S.S.S. \& MIRANDA, M.A.C. Aspectos da estrutura da raiz e do desenvolvimento de plantas de soja em solos compactados. Pesq. Agropec. Bras., 35:929-938, 2000.

RAMOS, B.Z.; PAIS, P.S.M.; FREITAS, W.A. \& JUNIOR, M.S.D. Avaliação dos atributos físico-hídricos em um Latossolo Vermelho distroférrico sob diferentes sistemas de manejo Lavras/Minas Gerais/Brasil. R. Ci. Agrár., 36:340-346, 2013.

REICHERT, J.M.; ALBUQUERQUE, J.A.; GUBIANI, P.I.; KAISER, D.R.; MINELLA, J.P.G. \& REINERT, D.J. Hidrologia do solo, disponibilidade de água às plantas e zoneamento agroclimático. In: FILHO, O.K.; MAFRA, A.L. \& GATIBONI, L.C., eds. Tópicos em ciência do solo. Viçosa, MG, Sociedade Brasileira de Ciência do Solo, 2011. v.7, p.1-54.

REICHERT, J.M.; SUZUKI, L.E.A.S.; REINERT, D.J.; HORN, R. \& HAKANSSON, I. Reference bulk density and critical degree-of-compactness for no-till crop production in subtropical highly weathered soils. Soil Till. Res., 102:242254, 2009.

REICHERT, J.M.; SUZUKI, L.E.A.S. \& REINERT, D.J. Compactação do solo em sistemas agropecuários e florestais: Identificação, efeitos, limites críticos e mitigação. In: CERETTA, C.A.; SILVA, L.S. \& REICHERT, J.M., eds. Tópicos Ciência do Solo. Viçosa, MG, Sociedade Brasileira de Ciência do Solo, 2007. v. 5, p.49-134.

ROSOLEM, C.A.; FERNANDEZ, E.M.; ANDREOTTI, M. \& CRUSCIOL, C.A.C. Crescimento radicular de plântulas de milho afetado pela resistência do solo à penetração. Pesq. Agropec. Bras., 34:821-828, 1999.

ROSOLEM, C.A.; ALMEIDA, A.C.S. \& SACRAMENTO, L.V.S. Sistema radicular e nutrição da soja em função da compactação do solo. Bragantia, 53:259-266, 1994.

SAS Institute Inc. SAS/STAT® 9.22 User's guide. Cary, 2010. 8445 p.
SECCO, D.; REINERT, D.J.; REICHERT, J.M. \& SILVA, V.R. Atributos físicos e rendimento de grãos de trigo, soja e milho em dois Latossolos compactados e escarificados. Ci. Rural, 39:58-64, 2009.

SILVA, G.J.; MAIA, J.C.S. \& BIANCHINI, A. Crescimento da parte aérea de plantas cultivadas em vaso, submetidas à irrigação subsuperficial e a diferentes graus de compactação de um Latossolo VermelhoEscuro distrófico. R. Bras. Ci. Solo, 30:31-40, 2006.

SUZUKI, L.E.A.S.; REICHERT, J.M.; REINERT, D. \& LIMA, C.L.R. Grau de compactação, propriedades físicas e rendimento de culturas em Latossolo e Argissolo. Pesq. Agropec. Bras., 42:1159-1167, 2007.

TAVARES FILHO, J.; BARBOSA, G.M.C.; GUIMARÃES, M.F. \& FONSECA, I.C.B. Resistência do solo a penetração e desenvolvimento do sistema radicular do milho (Zea mays) sob diferentes sistemas de manejo em um Latossolo Roxo. R. Bras. Ci. Solo, 25:725-730, 2001.

TAYLOR, H.M. \& BRAR, G.S. Effect of soil compaction on root development. Soil Till. Res., 19:111-119, 1991.

TAYLOR, H.M.; ROBERSON, G.M. \& PARKER, J.J. Soil strength-root penetration relations for medium-tocoarse-textured soil materials. Soil Sci., 102:18-22, 1966.

TORMENA, C.A.; ROLOFF, G. \& SÁ, J.C.M. Propriedades físicas do solo sob plantio direto influenciadas por calagem, preparo inicial e tráfego. R. Bras. Ci. Solo, 22:301-309, 1998.

van GENUCHTEN, M. Th. A closed-form equation for predicting the conductivity of unsaturated soils. Soil Sci. Soc. Am. J., 44:892-898, 1980.

XU, X.; NIEBER, J.L. \& GUPTA, S.C. Compaction effect on the gas diffusion coefficient in soils. Soil Sci. Soc. Am. J., 56:1743-1750, 1992. 